\title{
Prevalence and factors associated with unplanned pregnancy in a Brazilian capital in the Northeast
}

\author{
Ana Cleide Mineu Costa 1 \\ (iD https://orcid.org/0000-0003-0125-9535 \\ Bruno Luciano Carneiro Alves de Oliveira 2 \\ iD https://orcid.org/0000-0001-8053-7972 \\ Maria Teresa Seabra Soares de Britto e Alves 3 \\ iD https://orcid.org/0000-0002-4806-7752
}

\footnotetext{
1,3 Programa de Pós-graduação em Saúde Coletiva. Universidade Federal do Maranhão.São Luís, MA, Brasil.

2 Departamento de Medicina I. Universidade Federal do Maranhão. Praça Gonçalves Dias, 21. Centro, São Luís, MA, Brasil. CEP: 65.020-240. E-mail: oliveira.bruno@ufma.b
}

\begin{abstract}
Objectives: to analyze the prevalence and factors associated with unplanned pregnancy in a Brazilian capital in the Northeast.

Methods: a cross-sectional study nested to a hospital birth cohort with a probable sample of 5,110 puerperal women. Associated factors were analyzed using a hierarchical theoretical model in three levels: distal (women's socioeconomic and demographic characteristics), intermediate (reproductive characteristics, maternal habits and BMI), and proximal level (partner's characteristics). Multivariate Poisson regression analysis was performed.

Results: the prevalence of unplanned pregnancy was $68.1 \%(C 195 \%=66.8-69.4)$. Multivariate analysis showed association with black skin color $/$ race $(P R=1.03 ; C 195 \%=1.01$ 1.07), mother's age group up to 19 years old $(P R=1.09 ; C I 95 \%=1.06-1.12)$ and 20 to 24 years old $(P R=1.04 ; C 195 \%=1.01-1.07)$, not living with partner $(P R=1.09 ; C 195 \%=1.07-$ 1.11), highest number of people in the household: 5 people $(P R=1.10 ; C 195 \%=1.08-1.13)$ and 3 to $4(P R=1.08 ; C I 95 \%=1.05-1.10)$, number of $\geq 4$ children $(P R=1.09 ; C I 95 \%=1.06$ $1.13)$ and 2 or 3 children $(P R=1.03 ; C 195 \%=1.02-1.05)$, alcohol consumption $(P R=1.03$; $C I 95 \%=1.01-1.05)$, malnourished pre-pregnancy $B M I(P R=1.03 ; C 195 \%=1.01-1.06)$ and partner's low schooling (5 to 8 years) $(P R=1.03 ; C 195 \%=1.01-1.07)$. Prior abortion was inversely associated with planned pregnancy $(P R=0.95 ; C 195 \%=0.93-0.97)$.

Conclusions: the prevalence of unplanned pregnancy was high and was associated with socioeconomic and demographic characteristics that reflect on the combination of the complex inequalities that impact women and their partners
\end{abstract}

Key words Unplanned pregnancy, Reproductive planning, Reproductive health, Inequalitiess

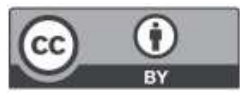




\section{Introduction}

Unplanned, unwanted, or unintended pregnancy by one or both partners is a public health indicator key and is the leading global reproductive health problem, causing significant physical, economic, social and psycho-emotional problems ${ }^{1-4}$ that negatively impact women, partners and children involved, both in current and future life cycles. ${ }^{2}$

Global, regional, and sub-regional estimates of unplanned pregnancy show that there has been a reduction in these estimates from 1995 to $2008^{3}$ and from 1990-1994 to 2010-2014.4 But the worst estimates remain in developing countries, especially in the African continent.3,4 In some cases, the estimates have even grown as in the South American and Caribbean sub-regions. 3,4 In 2008 alone, 208 million pregnancies were estimated, 185 million of which occurred in developing countries and 11.3 million in South America, of which $63.0 \%$ were unplanned. 3 Globally, 86 million pregnancies were unplanned, of which 33 million resulted in births and 41 million in abortions, half of the abortions occurred in unsafe situations and $98 \%$ were performed in developing countries.3,4 Between 2010 to 2014 there were about 99.1 million unplanned pregnancies per year, $23 \%$ of them resulted in unintended births and 56\% in abortions during this period. In South America, there were $72.0 \%$ of unplanned pregnancies. 4

Unplanned pregnancy increases the risk of maternal and infant morbidity and mortality. Women with this type of pregnancy have higher risks of depression, stress, suicide, poorer nutrition during pregnancy, instability in family relationships, physical and psychological violence, delayed initiation of prenatal care, more obstetric complications, abortion, and abortion-related to death, especially under unsafe conditions and in countries with restrictive abortion laws.3,5,6,7 Children born from unplanned pregnancies have worse perinatal and infant indicators, higher risks of infant death and up to five years of age have emotional, cognitive, depression, anxiety problems, higher school dropout rates, worse insertion in the labor market, involvement in social delinquency, risky behaviors such as licit and illicit drug abuse.5,6 Partners facing this type of pregnancy experience higher levels of stress, feelings of helplessness, and financial difficulties in managing life with the arrival of the new child. 7

High percentages of unplanned pregnancies remain even when contraceptive methods are available, either because of method failure, or low access to more modern methods, socioeconomic disadvantages, sexual violence or coercion in marital rela- tion. $4,5,8,9$ In several countries, a common profile of maternal characteristics has been associated with unplanned pregnancy, such as low schooling, lower income, no marital union, black or mixed skin color/race, age less than 20 years old, higher number of children, unhealthy habits and lifestyles.7,9-14 In Brazil, few population-based studies have been conducted demonstrating factors associated with unplanned pregnancy. 8,12 Also, no studies have been yet developed revealing the joint influence of the woman and her partner on socioeconomic and demographic characteristics in planning a current pregnancy in a theoretical model with data from specific contexts of the country. Mainly, among the most impoverished regions of the country such as the Brazilian Northeast. Among the cities in this region, the prevalence of unplanned pregnancies is higher and its occurrence depends even more on material living conditions and access to local health actions and services.

Therefore, this article analyzed the prevalence and factors associated with unplanned pregnancy in a Brazilian capital in the Northeast.

\section{Methods}

This is a cross-sectional study nested to a hospital birth cohort in the city of São Luís, Maranhão (MA), Brazil. This cohort is part of the Project "Fatores etiológicos do nascimento pré-termo e consequências dos fatores perinatais na saúde da criança: coorte de nascimento em duas cidades brasileiras" ("Etiological factors of preterm birth and consequences of perinatal factors on child health: birth cohort in two Brazilian cities") Brisa was conducted in São Luís, Maranhão and Ribeirão Preto, São Paulo. In this investigation only data from São Luís were included, which in 2010 IBGE demographic census registered 1,014,837 inhabitants. 15

This cohort was conducted in 2010 and included hospital births that occurred in public and private services, which performed more than one hundred births per year. The sample size was calculated based on the number of hospital births that occurred in 2008 , which represented $98 \%$ of all births in the city, enabling a representative sample of the population. For all births, a daily list was prepared in order of birth occurrence. The choice of puerperal women was systematic, every three women, with a random drawing starting in each maternity. The initial number drawn was added to the sample interval, resulting in a total sample of 5,451 births. There was a $4.6 \%$ of loss due to the mother's refusal and early discharge. After excluding twin births, the final 
sample was 5,110 births. More information about the general and sampling characteristics related to this research can be obtained in Silva et al. ${ }^{16}$

Unplanned pregnancy (yes or no) was considered as the dependent variable in response to the question: "Was the current pregnancy planned?". This type of pregnancy was considered when there was no conscious decision by the woman or couple. The unwanted and untimely categories were added to the unplanned pregnancy. The following covariates were selected: demographic variables - race/skin color (white, black and mixed), age $(\leq 19,20$ to 24 , 25 to 29 and 30 to 48 years old), age of partner ( $\leq 19$, 20 to 24,25 to 29 and $\geq 30$ years old), living with partner (yes/no); socioeconomic variables schooling (in years of study: 0 to 4.9 to 11 and $\geq 12$ years), economic class (A/B, C or D/E), which was defined according to the Critério de Classificação Econômica Brasil (Brazil Economic Classification Criterion) developed by the Associação Brasileira de Empresas de Pesquisa (ABEP)17 (Brazilian Association of Research Companies), family income in minimum wages $(<1$, from 1 to $3,>3$ to 5 and $>5$ ) living with a partner (yes/no) and living with children (yes/no); Women's reproductive health variables-previous abortion (yes/no); number of children $(\leq 3, \geq 4)$, previous premature delivery (yes/no), previous stillbirth (yes/no); behavioral variablesSmoking and alcohol consumption (yes/no); Prepregnancy Body Mass Index (BMI) (malnourished $<18.5$, eutrophic: 18.5 to 24.9 , overweight: 25 to 29.9 and obese: $\geq 30$ ).

The choice of variables was based on the literature and for the analysis of factors associated with unplanned pregnancy we used a theoretical model hierarchized in three levels: Distal, Intermediate and Proximal Block. The theoretical model and the variables that were included in each block are described in Figure 1. The theoretical model was built considering the influence of the variables in the following block.

Initially, absolute and percentage frequencies were estimated. Statistically significant differences were found in the prevalence of unplanned pregnancy according to the covariates when $\alpha<0.05$. Next, hierarchical modeling was performed using Poisson regression with robust variance, which allowed to estimate the Prevalence Ratio (PR) and 95\% Confidence Intervals (CI95\%). Modeling began with the first (distal) level variables. Variables with $p$-value $\leq 0.10$ at the immediate preceding level and were retained in the model. Variables of the proximal level were adjusted for the variables of the intermediate and distal levels. Data analysis was performed using Stata ${ }^{\circledR}$ software, version 13.0 .

The research was carried out after the approval by the Research Ethics Committee (REC) of the Hospital Universitário da UFMA through the consubstantiated Opinion number 223/2009 and the registration at the REC 350/08 and process number 4771/2008-30. After clarification of the risks and benefits of the research, the pregnant women were invited to sign the Informed Consent Term.

\section{Results}

Among 5,110 puerperal women, the prevalence of unplanned pregnancy was $68.1 \%$ (CI95\%=: 66.8$69.4)$. Most (32.0\%) were young women aged 20 to 24 years old, mixed skin color $(69 \%)$, belonging to class C $(53.8 \%)$, with 9 to 11 years of schooling $(58.0 \%)$, living with a partner $(80.5 \%)$ and with a monthly family income of up to 3 minimum wages $(57.8 \%)$. The household was of 3 to 4 people $(43.7 \%)$. The majority $(56.2 \%)$ reported the partner's schooling level of 9 to 11 years, with an age of over 30 years $(63.2 \%)$. Among those who did not plan a pregnancy, $78.3 \%$ were under 19 years old, $73.9 \%$ reported being black race/color, $84.1 \%$ did not live with their partner, $74.0 \%$ had 5 to 8 years of schooling, $70.7 \%$ had a family income of less than 1 minimum wage, $72.6 \%$ belonged to $\mathrm{D}$ and $\mathrm{E}$ economic class, $75.7 \%$ reported having more than five people in the household, $78.2 \%$ had a partner aged up to 19 years old and $74.0 \%$ had 5 to 8 years of schooling (Table 1).

Among the gestational characteristics, $49.8 \%$ of the women had one child, $14.8 \%$ had a previous premature delivery, $3.6 \%$ had a previous stillbirth, and $21.7 \%$ had a previous abortion. As for lifestyle habits, $9.6 \%$ smoked and $14.6 \%$ alcohol consumption. The women's previous BMI showed that $45.7 \%$ were eutrophic and $32.3 \%$ were obese. Of those who did not plan a pregnancy, $75.0 \%$ had the habit of smoking, $76.0 \%$ reported alcohol consumption, $78.0 \%$ had 4 or more children, $61.7 \%$ had a previous abortion, $66.1 \%$ had a previous stillborn, $74.2 \%$ had a previous premature delivery, and $74 \%$ were classified as pre-pregnancy BMI on malnutrition (Table 2).

Hierarchical multivariate analysis showed association of unplanned pregnancy with black color/race $(\mathrm{RP}=1.03 ; \mathrm{CI} 95 \%=1.01-1.07)$, mother's age group up to 19 years old $(\mathrm{RP}=1.09$; $\mathrm{CI} 95 \%=1.06-1.12)$ and 20 to 24 years old $(\mathrm{RP}=1.04$; CI95\%=1.01-1.07), not living with partner $(\mathrm{RP}=1.09 ; \mathrm{CI} 95 \%=1.07-1.11)$. The higher the number of people in the household, the higher the 
association, more than 5 people $(\mathrm{PR}=1.10$; $\mathrm{CI} 95 \%=$ $1.08-1.13)$ and 3 to $4(\mathrm{PR}=1.08 ; \mathrm{CI} 95 \%=1.05-1.10)$, at distal level. Economic class by asset index, income, and partner's age did not associate. At intermediate level, $\geq 4$ children ( $\mathrm{PR}=1.09$; $\mathrm{CI} 95 \%=1.06$ $1.13), 2$ or 3 children ( $P R=1.03$; CI95\%=1.02-1.05). Prior abortion was inversely associated with unplanned pregnancy. The following were not associated with the outcome: smoking habit, previous premature birth, previous stillbirth. At the proximal level, only partner's schooling of 5 to 8 years was associated $(\mathrm{RP}=1.03 ; \mathrm{CI} 95 \%=1.01-1.07)($ Table 3$)$.

\section{Discussion}

The results of this study indicated a high prevalence of unplanned pregnancy among puerperal women who participated in this cross-sectional study nested to a hospital birth cohort. A set of characteristics associated with this outcome was evidenced, such as black color/race, younger age group of the mother, not living with a partner, higher number of people in the household, higher number of previous children, alcohol consumption, pre-pregnancy BMI in the malnourished category, and the partner's schooling of 5 to 8 years. Similar to researches conducted in other countries and in regions of Brazil, these findings indicated that the occurrence of unplanned pregnancy reflects a combination of complex socioeconomic and health inequalities that impact women and their partners. However, it was observed that the prevalence and factors associated with the outcome investigated in the Capital under study show that this phenomenon is presented in an even more intense way and associated with living conditions and access to health in this State. Therefore, it offers important subsidies for the design of reproductive public health interventions and clinical assistance to women and partners of childbearing age.

Unplanned pregnancies are widely recognized as a cause and consequence of socioeconomic and health inequalities and are used as an indicator in

Figure 1

Theoretical hierarchical model.

DEMOGRAPHICS

Mother's skin colo

Live with partner

Maternal age

\begin{tabular}{|c|}
\hline MATERNAL HABITS \\
Smoking \\
Alcohol \\
\end{tabular}

REPRODUCTIVE LIFE

Number of children

Previous abortion

Previous premature

Previous stillbirths
OUTHERS MATERNAL FACTORS

Pre-pregnancy BMI
Proximal Level

Outcome
PARTNER

Partner's age

Partner's schooling
SOCIOECONOMIC

Maternal schooling

Family income

Possession of assets

umber of people in the household 
Puerperal women's socioeconomic and demographic characteristics according to pregnancy planning status. São Luís, MA. Brazil, 2010.

\begin{tabular}{|c|c|c|c|c|c|c|c|}
\hline & \multicolumn{4}{|c|}{ Planned pregnancy } & \multicolumn{2}{|c|}{ General Total } & \multirow[t]{3}{*}{$p^{\#}$} \\
\hline & \multicolumn{2}{|c|}{ Yes } & \multicolumn{2}{|c|}{ No } & \multirow[b]{2}{*}{$\mathrm{n}$} & \multirow[b]{2}{*}{$\%$} & \\
\hline & $\mathrm{n}$ & $\%$ & $n$ & $\%$ & & & \\
\hline Total & 1.630 & 31.9 & 3.480 & 68.1 & 5.110 & 100.0 & \\
\hline Skin color* & & & & & & & 0.001 \\
\hline White & 337 & 36.1 & 597 & 63.9 & 934 & 18.0 & \\
\hline Mixed & 1.118 & 31.9 & 2.391 & 68.1 & 3.509 & 69.0 & \\
\hline Black & 171 & 26.1 & 484 & 73.9 & 655 & 13.0 & \\
\hline Age group (years) & & & & & & & 0.001 \\
\hline Upto 19 & 201 & 21.1 & 750 & 78.9 & 951 & 19.0 & \\
\hline $20-24$ & 488 & 29.8 & 1.147 & 70.2 & 1.635 & 32.0 & \\
\hline $25-29$ & 460 & 34.4 & 878 & 65.6 & 1.338 & 26.0 & \\
\hline 30 or more & 479 & 40.7 & 699 & 59.3 & 1.178 & 23.0 & \\
\hline Live with partner & & & & & & & 0.001 \\
\hline Yes & 1.470 & 35.8 & 2.637 & 64.2 & 4.107 & 80.5 & \\
\hline No & 158 & 15.9 & 837 & 84.1 & 995 & 19.5 & \\
\hline Schooling (years)* & & & & & & & 0.001 \\
\hline 12 or more & 337 & 44.1 & 427 & 55.9 & 764 & 15.0 & \\
\hline $9-11$ & 926 & 31.4 & 2.026 & 68.6 & 2.952 & 58.0 & \\
\hline $5-8$ & 295 & 26.0 & 843 & 74.0 & 1.138 & 22.0 & \\
\hline $0-4$ & 66 & 28.2 & 168 & 71.8 & 234 & 5.0 & \\
\hline Income (minimum wage)** & & & & & & & 0.001 \\
\hline$>5$ & 316 & 42.8 & 423 & 57.2 & 739 & 17.6 & \\
\hline More than $3-5$ & 129 & 29.3 & 311 & 70.7 & 440 & 10.5 & \\
\hline $1-3$ & 729 & 30.7 & 1.645 & 69.3 & 2.374 & 57.8 & \\
\hline$<1$ & 209 & 33.1 & 421 & 66.9 & 630 & 15.1 & \\
\hline Economic class* & & & & & & & 0.001 \\
\hline$A / B$ & 392 & 42.7 & 526 & 57.3 & 918 & 19.2 & \\
\hline $\mathrm{C}$ & 812 & 31.5 & 1.769 & 68.5 & 2.581 & 53.8 & \\
\hline $\mathrm{D} / \mathrm{E}$ & 355 & 27.4 & 943 & 72.6 & 1.298 & 27.0 & \\
\hline People in the household & & & & & & & 0.001 \\
\hline 1 - 2 people & 554 & 43.4 & 723 & 56.6 & 1.277 & 25.0 & \\
\hline 3 - 4 people & 686 & 30.8 & 1.542 & 69.2 & 2.228 & 43.7 & \\
\hline$>5$ people & 388 & 24.3 & 1.209 & 75.7 & 1.597 & 31.3 & \\
\hline Partner's age (years) & & & & & & & 0.003 \\
\hline Upto 19 & 22 & 21.8 & 79 & 78.2 & 101 & 2.0 & \\
\hline $20-24$ & 247 & 31.3 & 542 & 68.7 & 789 & 15.4 & \\
\hline $25-29$ & 358 & 36.2 & 632 & 63.8 & 990 & 19.4 & \\
\hline 30 or more & 1.001 & 31.0 & 2.221 & 69.0 & 3.222 & 63.2 & \\
\hline Partner's schooling (years) & & & & & & & 0.001 \\
\hline 12 or more & 312 & 43.5 & 405 & 56.5 & 717 & 15.4 & \\
\hline 9 or 11 & 886 & 33.8 & 1.738 & 66.2 & 2.624 & 56.2 & \\
\hline 5 or 8 & 245 & 26.0 & 698 & 74.0 & 943 & 20.2 & \\
\hline 0 or 4 & 101 & 26.3 & 283 & 73.7 & 384 & 8.2 & \\
\hline
\end{tabular}

\# Pearson's chi-square test; *except if ignored, **Minimum Wage $\mathrm{R} \$ 510,00$. 
Table 2

Puerperal women's reproductive characteristics, life habits and pre-pregnancy BMI according to pregnancy planning status. São Luís, MA. Brazil. 2010.

\begin{tabular}{|c|c|c|c|c|c|c|c|}
\hline & \multicolumn{4}{|c|}{ Planned pregnancy } & \multicolumn{2}{|c|}{ General Total } & \multirow[t]{3}{*}{$p^{\#}$} \\
\hline & \multicolumn{2}{|c|}{ Yes } & \multicolumn{2}{|c|}{ No } & \multirow[b]{2}{*}{$\mathrm{n}$} & \multirow[b]{2}{*}{$\%$} & \\
\hline & $\mathrm{n}$ & $\%$ & $\mathrm{n}$ & $\%$ & & & \\
\hline Smoking habit & & & & & & & 0.001 \\
\hline No & 1,506 & 32.6 & 3.106 & 67.4 & 4,612 & 90.4 & \\
\hline Yes & 122 & 25.0 & 366 & 75.0 & 488 & 9.6 & \\
\hline Drinking habit & & & & & & & 0.001 \\
\hline No & 1,450 & 33.3 & 2.909 & 66.7 & 4,359 & 85.4 & \\
\hline Yes & 178 & 24.0 & 565 & 76.0 & 743 & 14.6 & \\
\hline Number of children* & & & & & & & 0.001 \\
\hline First & 865 & 34.3 & 1.659 & 65.7 & 2,524 & 49.8 & \\
\hline 2 or 3 & 656 & 30.5 & 1.498 & 69.5 & 2,154 & 42.5 & \\
\hline 4 or more & 85 & 22.0 & 302 & 78.0 & 387 & 7.7 & \\
\hline Previous abortion & & & & & & & 0.001 \\
\hline No & 1,204 & 30.0 & 2.791 & 70.0 & 3,995 & 78.3 & \\
\hline Yes & 424 & 38.3 & 683 & 61.7 & 1,107 & 21.7 & \\
\hline Previous stillbirth & & & & & & & 0.533 \\
\hline No & 1,556 & 31.8 & 3.353 & 68.2 & 4,919 & 96.4 & \\
\hline Yes & 62 & 33.9 & 121 & 66.1 & 183 & 3.6 & \\
\hline Previous premature birth* & & & & & & & 0.859 \\
\hline No & 1,362 & 31.9 & 2.949 & 68.1 & 4,331 & 85.2 & \\
\hline Yes & 241 & 31.9 & 514 & 68.1 & 755 & 14.8 & \\
\hline Pre-pregnancy BMI & & & & & & & 0.001 \\
\hline Malnourished & 128 & 25.8 & 369 & 74.2 & 497 & 9.7 & \\
\hline Eutrophic & 802 & 34.4 & 1.531 & 65.2 & 2,333 & 45.7 & \\
\hline Overweight & 243 & 38.7 & 385 & 61.3 & 628 & 12.3 & \\
\hline Obese & 455 & 27.7 & 1.189 & 72.3 & 1,644 & 32.3 & \\
\hline
\end{tabular}

\# Pearson's chi-square test; *except ignored.

Table 3

Hierarchical multivariate analysis of factors associated with unplanned pregnancy in puerperal women. São Luís, MA. Brazil, 2010.

\begin{tabular}{|c|c|c|c|c|c|}
\hline & \multicolumn{2}{|c|}{ Unplanned pregnancy } & \multirow[t]{2}{*}{ PR } & \multirow[t]{2}{*}{ Cl95\% } & \multirow[t]{2}{*}{$p^{\#}$} \\
\hline & $\mathrm{N}$ & $\%$ & & & \\
\hline \multicolumn{6}{|l|}{ Distal Level } \\
\hline Skin color\#\# & & & & & 0.001 \\
\hline White & 587 & 63.9 & Ref. & & \\
\hline Black & 494 & 73.9 & 1.03 & $1.01-1.07$ & \\
\hline Mixed & 2,391 & 68.1 & 0.99 & $0.97-1.01$ & \\
\hline Age(years)\#\# & & & & & $<0.001$ \\
\hline 30 or more & 699 & 59.3 & Ref. & & \\
\hline $25-29$ & 874 & 65.6 & 1.02 & $0.99-1.04$ & \\
\hline $20-24$ & 1,147 & 70.2 & 1.04 & $1.01-1.07$ & \\
\hline Upto 19 & 750 & 78.8 & 1.09 & $1.06-1.12$ & \\
\hline Live with partner & & & & & $<0.001$ \\
\hline Yes & 2,637 & 64.2 & Ref. & & \\
\hline No & 837 & 84.1 & 1.09 & $1.07-1.11$ & \\
\hline
\end{tabular}


Hierarchical multivariate analysis of factors associated with unplanned pregnancy in puerperal women. São Luís, MA. Brazil, 2010.

\begin{tabular}{|c|c|c|c|c|c|}
\hline & \multicolumn{2}{|c|}{ Unplanned pregnancy } & \multirow[t]{2}{*}{ PR } & \multirow[t]{2}{*}{$\mathrm{Cl} 195 \%$} & \multirow[t]{2}{*}{$p^{\#}$} \\
\hline & $\mathrm{N}$ & $\%$ & & & \\
\hline \multicolumn{6}{|l|}{ Distal Level } \\
\hline Schooling in years\#\# & & & & & 0.770 \\
\hline 12 or more & 427 & 55.9 & Ref. & & \\
\hline $9-11$ & 2,026 & 68.6 & 1.01 & $0.98-1.04$ & \\
\hline $5-8$ & 843 & 74.6 & 1.01 & $0.98-1.05$ & \\
\hline $0-4$ & 168 & 71.8 & 1.01 & $0.96-1.07$ & \\
\hline Income in minimum wages*\#\# & & & & & 0.373 \\
\hline 5 or more & 423 & 57.2 & Ref. & & \\
\hline$>3$ to 5 & 311 & 70.7 & 1.02 & $0.98-1.05$ & \\
\hline 1 to 3 & 1,645 & 69.3 & 1.02 & $0.98-1.05$ & \\
\hline$<1$ & 421 & 66.9 & 1.00 & $0.95-1.04$ & \\
\hline Class by assets ownership\#\# & & & & & 0.075 \\
\hline$A / B$ & 526 & 57.3 & Ref. & & \\
\hline $\mathrm{C}$ & 1,769 & 68.5 & 1.02 & $0.99-1.05$ & \\
\hline $\mathrm{D} / \mathrm{E}$ & 943 & 72.6 & 1.04 & $1.01-1.08$ & \\
\hline People in the household\#\# & & & & & $<0.001$ \\
\hline 1 - 2 people & 723 & 56.6 & Ref. & & \\
\hline 3 - 4 people & 1,522 & 69.2 & 1.08 & $1.05-1.10$ & \\
\hline More than 5 people & 1,209 & 75.7 & 1.10 & $1.08-1.13$ & \\
\hline \multicolumn{6}{|l|}{ Intermediate Level } \\
\hline Smoking habit & & & & & 0.148 \\
\hline No & 3,106 & 67.4 & Ref. & & \\
\hline Yes & 366 & 78.0 & 1.01 & $0.99-1.04$ & \\
\hline Drinking habit & & & & & 0.005 \\
\hline No & 2,909 & 66.7 & Ref. & & \\
\hline Yes & 565 & 76.0 & 1.03 & $1.01-1.05$ & \\
\hline Number of children\#\# & & & & & $<0.001$ \\
\hline First & 1,559 & 65.7 & Ref. & & \\
\hline 2 or 3 & 1,498 & 69.5 & 1.03 & $1.02-1.05$ & \\
\hline 4 or more & 302 & 78.0 & 1.09 & $1.06-1.13$ & \\
\hline Previous abortion & & & & & $<0.001$ \\
\hline No & 2,791 & 70.0 & Ref. & & \\
\hline Yes & 683 & & 61.7 & 0.95 & $0.93-0.97$ \\
\hline Previous premature birth\#\# & & & & & 0.555 \\
\hline No & 2,949 & 68.1 & Ref. & & \\
\hline Yes & 514 & 68.1 & 0.99 & $0.97-1.01$ & \\
\hline Previous stillbirth\#\# & & & & & 0.656 \\
\hline No & 121 & 66.1 & Ref. & & \\
\hline Yes & 3,353 & 68.2 & 0.99 & $0.94-1.03$ & \\
\hline Pre-pregnancy BMI & & & & & 0.033 \\
\hline Eutrophic & 1,531 & 65.6 & Ref. & & \\
\hline Malnourished & 369 & 74.2 & 1.03 & $1.01-1.06$ & \\
\hline Overweight & 385 & 61.3 & 0.98 & $0.96-1.01$ & \\
\hline Obesity & 1,189 & 72.3 & 1.00 & $0.99-1.02$ & \\
\hline
\end{tabular}

\# Pearson's chi-square test; \#\#except ignored, * Minimum Wage R\$510.00. 
Hierarchical multivariate analysis of factors associated with unplanned pregnancy in puerperal women. São Luís, MA. Brazil, 2010.

\begin{tabular}{lccccc}
\hline & \multicolumn{2}{c}{ Unplanned pregnancy } & PR & C195\% & $p^{\#}$ \\
\cline { 2 - 3 } & $\mathrm{N}$ & $\%$ & & \\
\hline Proximal Level & & & & \\
Partner's age (in years) & & & & \\
$\quad 30$ or more & 2,221 & 69.0 & Ref. & & \\
$25-29$ & 632 & 63.8 & 0.99 & $0.96-1.01$ & \\
$20-24$ & 542 & 68.7 & 0.99 & $0.97-1.02$ & \\
Up to 19 & 79 & 78.2 & 1.04 & $0.99-1.10$ & \\
Partner's education (in years) & & & & & \\
12 or more & 405 & 56.5 & Ref. & & \\
$9-11$ & 1,738 & 66.2 & 1.01 & $0.99-1.04$ & \\
$5-8$ & 698 & 74.0 & 1.03 & $1.01-1.07$ & \\
$0-4$ & 283 & 73.7 & 0.99 & $0.95-1.03$ & \\
\hline
\end{tabular}

\# Pearson's chi-square test; \#\#except ignored, * Minimum Wage R\$510.00.

monitoring the impact and effectiveness of family planning programs. In the U.S., the economic costs of unplanned pregnancies are estimated to be $\$ 9.6$ to $\$ 12.6$ billion annually, with an average cost of $\$ 9,000$ per woman. Actions to reduce the prevalence of these pregnancies could produce savings of about $\$ 5.6$ billion a year. ${ }^{2}$

In the world, studies on pregnancy planning status among women that lead up to birth as in the present study are not frequent. However, in projections and surveys where the question about pregnancy planning status was asked at different points in women's lives, a reduction in the prevalence and rate of unplanned pregnancies has been observed in several countries. However, they still remain high, especially in developing countries. Between 1990$1994(59.0 \%$; CI90\%=55-64) to 2010-2014 (69.0\%; CI90\% $=64-76$ ) Latin America was the only region in which the prevalence of births from unintended pregnancies increased substantially, 4 and the Caribbean and South America were the subregions of the world that showed the smallest declines in this rate per 1,000 women aged 15-44, remaining in this same period with the first and fourth highest rates, respectively. When analyzed in aggregate between 1995 and 2008, Latin America and the Caribbean remained with the highest prevalence and rates of unplanned pregnancy in the world. 3

Different surveys have found similar prevalence to that observed in this analysis. In Brazil, a survey conducted between 2011-2012, identified 55.4\% of unplanned pregnancies. ${ }^{8}$ In Rio Grande, Rio Grande do Sul $65 \%, 12$ a multicenter study in Ecuador $62.7 \%, 18$ a cohort of $\mathrm{HIV}^{+}$pregnant women in South
Africa (72\%). ${ }^{7}$ However, the prevalence in our study was higher than estimated in some U.S. States $(39.7 \%)$ and in a survey conducted in Australia $(23.8 \%$; CI95\%=22.0-25.6), 14 Nigeria $(27.7 \%$; CI95\% $=26.1-29.3), 19$ Great Britain (16.2\%; CI95\% $=13.1-19.9), 13$ France $(33.3 \%)$, Spain $(40 \%) 13$ and the U.S. $\left(16.0 \%\right.$; CI95\%=9.0-25.0). ${ }^{13}$

In relation to those observed in the Capital, data source under study, such differences in prevalence are due to individual and contextual socioeconomic, behavioral, and health factors. Contraception and abortion services that are easily available, better structured, and financially subsidized by developed country governments may have reduced the rate and prevalence of unintended pregnancies in these locations. Study indicates that in the group of countries where abortion is either totally prohibited by law or allowed only to save the woman's life, $48 \%$ $(\mathrm{CI} 95 \%=45-54)$ of unintended pregnancies ended in abortion in 2010-2014. This proportion was substantially higher, $69 \%(\mathrm{CI} 95 \%=62-74)$, in countries where abortion is allowed on demand. 4 Family planning programs have increased the prevalence of contraceptive use in countries regardless of their stage of development. The proportion of married women using contraception (modern or traditional) in developing countries increased by $8 \%$ (54\% to $62 \%$ ) between 1990 and 2014 (with most of the increase occurring in the first decade of this 25-year study period). In addition, among contraceptive method users, the proportion using modern methods rather than traditional methods increased. ${ }^{4}$ However, the decline in the rate of unintended pregnancy in developing regions is still far from that desired and 
that observed in developed countries, in part because of unequal access to and use of contraceptives, especially modern contraceptives. Estimates worldwide indicate that if all non-users and all women using traditional methods started using modern methods, about 54 million unintended pregnancies would be avoided annually, including 22 million unintended births and 25 million abortions. ${ }^{3}$ The high prevalence verified in this research is worrisome, since this is a city with marked socioeconomic inequalities and where maternal mortality is still high, 107.15 deaths per thousand live births in 2013,22 and unplanned pregnancy tends to expose women to various obstetric risk situations.

Our findings are consistent with other studies that have indicated that unplanned pregnancies are higher and more likely to occur among adolescent and younger women, with a higher number of previous children, unmarried, of lower socioeconomic status, and with deleterious health behaviors, such as alcohol consumption.7,14,19 However, this study added to the debate the fact that these determinants are structured in a hierarchical theoretical model, incorporating the influence of paternal variables in the occurrence of the outcome. The results indicated at each level the disposition of associated variables. At the proximal level, black color/race women, adolescent and younger, who do not live with their partner, presented a higher number of people residing in the household. At the intermediate level, those who consumed alcohol, had more children, malnutrition status before pregnancy. At the proximal level, only the partner's low level of schooling increased the chance of not planning a pregnancy. The age of the partner did not influence pregnancy planning. However, at the intermediate level, prior abortion increased the chance of planning the current pregnancy. On one hand, it is possible that prior abortion favors women's awareness of the need for fertility control and future sexual planning. This finding was similar to that observed in South Brazil. 8 On the other hand, it is possible that women who have not aborted yet are in early unplanned pregnancies, while those who have aborted persist without control of their high fertility, but in lower volume. Indicating a strong association with contextual characteristics with the maintenance of an unplanned pregnancy. Studies conducted in other countries point to the association of the current unplanned pregnancy with 3 to 5 previous abortions. 7

Several studies $10,12,21$ confirm the finding that black women have a higher chance of unintended pregnancy, a fact that suggests unequal access of these women in the full exercise of their reproductive rights. Maternal schooling was not associated, as in studies carried out in Rio Grande do Sul12 and Bahia. ${ }^{22}$ However, other studies found a positive association with low maternal schooling. 7,11,14,19

Women who begin motherhood in adolescence tend to have a greater number of children during their reproductive life, and most of them have an unplanned first pregnancy. Those who are younger are more likely to have an unplanned pregnancy due to the difficult access to contraceptive methods and lack of sexual education, especially during adolescence. Therefore, there is, the need to implement differentiated and effective actions of reproductive planning for this group, since in Brazil, the actions are focused more on adult women.

It was observed that women who do not live with their partners are more likely to have unplanned pregnancies, suggesting the need for family structure as a condition for pregnancy planning. $12 \mathrm{~A}$ previous study found that eventual sexual relations, which usually occur in unstable relationships, lead to nonuse of contraceptive methods and consequently to unplanned pregnancy. 13 In relation to the household, the higher the number of people, the higher is the chance of unplanned pregnancy, a result in accordance with a study from the South of Brazil, 12 which suggests that structural, sociocultural inequalities, poverty and the lack of planning to define the size of the families would justify the pregnancies remaining unplanned. Pre-pregnancy BMI in the malnourished category increased the chances of unplanned pregnancy, which has already been shown in another study. ${ }^{8}$ Also, alcohol consumption is well defined in the literature as a major vulnerability factor for unplanned pregnancy. Studies show 7,23 that women who do not plan their pregnancies consume more alcohol than those who plan. This set of associations are worrisome, since women who have more children attend health services more often, offering greater opportunities for professionals to provide guidance on contraception, modification in behaviors harmful to health and safe eating, which may indicate the fragility of the contraceptive care offered to the women assessed.

An association of unplanned pregnancy with the partner's schooling was evidenced in the 5 to 8 years range. When investigating paternity among young people, a study in Pelotas, RS found similar results, being higher in the 0 to 4 years of study range. 24 This association suggests that women may find it more difficult to negotiate with their partners about contraceptive use, or compounds women's difficulties in accessing and using reproductive health 
methods and information.

Despite these results, it is worth to point out some of its limitations. Cross-sectional studies simultaneously measure risk and protective factors and the outcome. Therefore, this may weaken the understanding of the direction of some associations. However, the use of the theoretical model in this analysis indicates the direction of the expected association. The natural ambivalence during pregnancy and after delivery to the desire for pregnancy, and the feelings and reactions to the presence of the newborn may have altered the classification of pregnancy and attenuated or increased the prevalence of the unplanned pregnancy condition. The outcome estimate was obtained by means of a dichotomous question. Unintended pregnancy is conceptually and practically a complex construct. There is no single term that captures the nuances of what it means. 13 There is now recognition that more advanced and appropriate methods better capture and refine the complexity of pregnancy planning status, such as treating planning status as a continuum and using multi-item measures for classification. 13 The database used in this research did not include information on sexual behavior and urban-rural place of residence, which in part limited the control for these factors in the analyses performed. However, these limitations do not reduce the relevance of the findings, because unlike most research that is based on retrospective studies, in which information about pregnancy planning is obtained well after pregnancy and birth, the data in this research were obtained from puerperal women participating in a populationbased birth cohort study. In addition, a theoretical model was used to define the structure of the relationship between covariates and the study outcome, incorporating the simultaneous influence of maternal and paternal characteristics in the analysis. The absence of a theoretical model to analyze these relationships has been one of the most important limitations pointed out. 9

This study identified that unplanned pregnancy is still substantially high and was associated with socioeconomic, demographic, and behavioral characteristics that reflect the combination of complex inequalities that impact women and their partners. It shows that populations of more vulnerable puerperal women, younger, residing in more precarious households, with larger families are the most affected by unplanned pregnancies; suggesting that overcoming these inequalities represents an important way to reduce the prevalence of the outcome under study.

Thus, sexual and reproductive health services are needed to help women and their partners to avoid unintended pregnancies and ensure healthier outcomes for those who experienced these pregnancies until the birth of their children. The results indicated the necessity to improve the quality of reproductive planning, through comprehensive actions in the health network, ensuring access to information and modern contraceptive methods, encouraging adherence to healthier behaviors, strengthening the agency of women on their fertility control, implementation of adequate assistance in primary care for men, women and adolescents, in order to promote the full exercise of reproductive and sexual rights and reduce the risks and harms associated with unintended pregnancies affecting women, partners and children in various life cycles.

\section{Acknowledgements}

We would like to thank the Coordenação de Aperfeiçoamento de Pessoal de Nivel Superior (CAPES - funding code 001, Brazil) and the Fundação de Amparo à Pesquisa e ao Desenvolvimento Científico e Tecnológico do Maranhão (FAPEMA).

\section{Authors' contribution}

Costa ACM and Alves MTSSB participated equally in the study design, data analysis, interpretation of the results, writing of the manuscript. Oliveira BLCA participated in the discussion of the results, writing and critical revision of the paper. All authors approved the final version of the article. 


\section{References}

1. Wichmann, M. R. The influence of reproductive information quality on the probability of unplanned and unwanted pregnancies in Brazil. J Bras Econ Saúde. 2019; 11 (1): 3-9.

2. Monea E, Thomas A. Unintended Pregnancy and Taxpayer Spending. Perspect Sex Reprod Health. 2011; 43 (2): 8893.

3. Singh S, Sedgh G, Hussain R. Unintended Pregnancy: Worldwide Levels, Trends, and Outcomes. Stud Fam Plann. 2010; 41 (4): 241-50.

4. Bearak J, Popinchalk A, Alkema L, Sedgh G. Global, regional, and subregional trends in unintended pregnancy and its outcomes from 1990 to 2014:estimates from a Bayesian hierarchical model. 2018; Lancet Global Health. 6: e380-89.

5. Yazdkhasti M, Pourreza A, Pirak A, Abdi F. Unintended Pregnancy and Its Adverse Social and Economic Consequences on Health System: A Narrative Review Article. Iran J Public Health. 2015; 44 (1): 12-21.

6. Herd P, Higgins J, Sicinski K, Merkurieva I. The Implications of Unintended Pregnancies for Mental Health in Later Life. Am J Public Health. 2016; 106 (3): 421-9.

7. Adeniyi OV, Ajayi, AI, Moyaki MG, Goon DT, Avramovic G, Lambert J. High rate of unplanned pregnancy in thecontext of integrated family planning and HIV care services in South Africa. 2018; 18: 140-7.

8. Brandão ER, Cabral CS. Da gravidez imprevista à contracepção: aportes para um debate. Cad Saúde Pública. 2017 33 (2): e00211216

9. Macleod CI. Public reproductive health and 'unintended' pregnancies:introducing the construct 'supportability'. J Public Health. 2015; 38 (3): 84-91.

10. Foster DG, Raifman SE, Gipson JD, Rocca CH, Biggs MA. Effects of Carrying an Unwanted Pregnancy to Term on Women's Existing Children. J Pediatrics. 2019; 205 (2): 183-9.

11. Barton K, Redshaw M, Quigley MA, Carson C. Unplanned pregnancy and subsequent psychological distress in partnered women: a cross-sectional study of the role of relationship quality and wider social support. BMC Pregnancy Childbirth. 2017; 17: 44

12. Prietsch SOM, Gonzalez-Chica DA, Cesar JÁ, MendozaSassi RA.Gravidez não planejada no extremo Sul do Brasil: prevalência e fatores associados. Cad Saúde Pública. 2011; 27 (10): 1906-16.

13. Wellings $\mathrm{K}$, Jones KG, Mercer $\mathrm{CH}$, Tanton C, Clifton S, Datta J,Copas AJ, Erens B, Gibson LJ, Macdowall W, Sonnenberg P, Phelps A, Johnson AM. The prevalence of unplanned pregnancy and associated factors in Britain: findings from the third National Survey of Sexual Attitudes and Lifestyles (Natsal-3). Lancet. 2013; 382: 1807-16.
14. Rowe H, Holton S, Kirkman M, Bayly C, Jordan L, McNamee K,McBain J, Sinnott V, Fisher. Prevalence and distribution of unintended pregnancy: the Understanding Fertility Management in Australia National Survey. Int J Sex Health. 2014; 26: 100-12.

15. IBGE (Instituto Brasileiro de Geografia e Estatística). Censo demográfico 2010: características da população e dos domicílios, resultados do universo. Rio de Janeiro; 2011.

16. Silva AAM, Batista RFL, Simões VMF, Thomaz EBAF, Ribeiro CCC, Lamy Filho F, Lamy ZC, Alves MTSSB, Loureiro FHF, Cardoso VC, Bettiol H, Barbieri MA. Changes in perinatal health in two birth cohorts $(1997 / 1998$ and 2010) in São Luís, Maranhão State, Brazil. Cad Saúde Pública. 2015; 31: 1437-50.

17. ABEP (Associação Brasileira de Empresas de Pesquisa). Critério de Classificação Econômica Brasil. [acesso 12 abr 2018]. Disponível em: http://www.abep.org

18. Goicolea I, San Sebastian M. Unintended pregnancy in the amazon basin of Ecuador: a multilevel analysis. Int J Equity Health. 2010; 9: 14

19. Sedgh G, Bankole B. Unwanted Pregnancy and Associated Factors Among Nigerian Women. Int Family Plann Perspect. 2006; 32 (4): 175-84.

20. Brasil, Ministério da Saúde. Data SUS. Indicadores e dados básicos. 2013. [acesso 30 mar 2019]. Disponível em: http://tabnet.datasus.gov.br/cgi/f08.def

21. Goodman M, Onwumere O, Milam L, Peipert JF. Reducing health disparities by removing cost, access, and knowledge barriers. Am J Obstet Gynecol. 2017; 216: 382.e1-5.

22. Coelho EAC, Andrade MLS, Vitoriano LVT, Souza JJ, Silva DO, Gusmão MEN, Nascimento ER, Almeida MS Associação entre gravidez não planejada e o contexto socioeconômico de mulheres em área da Estratégia Saúde da Família. Acta Paul Enferm. 2012; 25 (3): 415-22.

23. Massaro LTS, Abdalla RR, Laranjeira R, Caetano R, Pinsky I, Madruga CS. Alcohol misuse among women in Brazil: recent trends and associations with unprotected sex, early pregnancy, and abortion. Braz J Psychiatry. 2019; 41 (2) 131-7.

24. Gigante DP. Maternidade e paternidade na coorte de nascimentos de 1982 a 2004-5, Pelotas, RS. Rev Saúde Pública. 2008; 42 (supl. 2): 42-50.
Received on May 17, 2019

Final version submitted on November 24, 2020

Approved on February 19, 2021 